\title{
Utilização de revestimento biodegradável a base de resíduo de frutas e hortaliças na conservação de cenoura (Daucus carota $\mathbf{L}$.) minimamente processada.
}

\author{
SOUZA, M.R.A. ; FAI, A.E.C. ${ }^{1,2}$; N.V.BRUNO ${ }^{1}$; GONÇALVES, E.C.B.A. ${ }^{1,2}$ \\ ${ }^{1}$ Departamento de Tecnologia de Alimentos, Escola de Nutrição, Universidade Federal do \\ Estado do Rio de Janeiro, Brasil; ${ }^{2}$ Programa de Pós-graduação de Alimentos e Nutrição, \\ Universidade Federal do Estado do Rio de Janeiro, Brasil \\ E-mail para contato: ediracba@analisedealimentos.com.br
}

\begin{abstract}
RESUMO - Esta pesquisa objetivou avaliar a aplicação de um revestimento biodegradável em cenoura ralada (Daucus carota L.) utilizando uma solução filmogênica a base de resíduo industrial de frutas e hortaliças. Esta foi preparada mediante a extração aquosa da farinha do resíduo em uma concentração de $8 \%(\mathrm{p} / \mathrm{v})$. As análises de perda de massa, cor, acidez total titulável e $\mathrm{pH}$ foram realizadas a cada três dias. As amostras com e sem revestimento apresentaram comportamento semelhante quanto às características químicas e físico-químicas. No entanto, verificou-se que o revestimento reduziu significativamente $(\mathrm{p}>0,05)$ o índice de esbranquiçamento da amostra revestida, comparado ao grupo controle, em 12 dias de armazenamento com temperatura controlada $\left(5^{\circ} \mathrm{C}\right)$. Uma vez que o revestimento é oriundo do resíduo de frutas e hortaliças, acredita-se que o próprio revestimento é ainda capaz de agregar valor funcional, bem como sabor e aroma à cenoura minimamente processada. Assim, concluiu-se que a solução filmogênica aplicada apresenta potencial como revestimento de vegetais minimamente processados e segue sendo avaliada, visando verificar sua ação protetora de compostos bioativos e influência nas características sensoriais e microbiológicas do vegetal revestido.
\end{abstract}

\section{INTRODUÇÃO}

A procura por produtos prontos para consumo, com qualidade de frescos e contendo apenas ingredientes naturais tem crescido constantemente devido a mudanças no estilo de vida dos consumidores (Alarcón-Flores et al., 2014; Ahmed et al., 2011; Pereira et al., 2008). Dentre esses produtos citam-se os vegetais minimamente processados.

Das hortaliças minimamente processadas a cenoura é uma das mais populares pela sua versatilidade de uso e formas de apresentação ao consumidor, sendo um dos produtos mais utilizados na indústria do processamento mínimo, justificando-se a importância do desenvolvimento de 
estratégias para aprimorar e aumentar a vida de prateleira de seus derivados minimamente processados (Porta et al., 2013).

Uma das estratégias para estender a vida de prateleira desses vegetais é através da aplicação de revestimentos comestíveis, com o intutito de reduzir a perda de umidade, formar barreira ao contato com oxigênio, diminuir as taxas de respiração, retardar a produção de etileno e impedir a perda de compostos voláteis (Azeredo et al., 2012). Quando esses revestimentos são constituídos por compostos com bioatividade, pode-se ainda agregar valor a esses produtos carreando aditivos que retardem a descoloração e o crescimento bacteriano entre outras ações (Du et al., 2011).

Apesar de alguns pesquisadores terem relatado a utilização de frutas e hortaliças como matéria-prima para a para elaboração de revestimentos e embalagens biodegradáveis (Azeredo et al., 2012; Du et al., 2011; Martelli et al., 2011) poucos trabalhos associam o uso de resíduos orgânicos como talos, cascas e sementes como fontes alternativas para este fim (Ooi et al., 2012; Barbosa et al., 2011; Park e Zhao, 2006). Tal uso está relacionado à presença de polissacarídeos em sua composição, como pectina, amido e derivados de celulose, que apresentam capacidade filmogênica, formando matrizes coesas com uma variedade de açúcares, que podem atuar como plastificantes naturais (Martelli et al., 2011).

Assim, esta pesquisa teve como objetivo aplicar um revestimento biodegradável em cenoura minimamente processada ralada (Daucus carota L.) utilizando uma solução filmogênica a base de resíduo industrial de frutas e hortaliças e avaliar sua eficiência para estender a vida de prateleira da mesma.

\section{METODOLOGIA}

\subsection{Fabricação da farinha de resíduos de frutas e hortaliças (FFH)}

A FFH foi produzida segundo método estabelecido por Ferreira et al. 2013. As frutas e utilizadas foram: laranja seleta (Citrus sinensis), maracujá (Passiflora edulis) e melancia (Citrullus lanatus). As hortaliças utilizadas foram: abobrinha (Cucúrbita pepo), alface (Lactuca sativa), cenoura (Daucus carota), espinafre (Spinacea oleracea), hortelã (Mentha s.p.), inhame (Colocasia esculenta), pepino (Cucumis sativus) e rúcula (Eruca sativa). Todas as amostras foram adquiridas em um supermercado local (Rio de Janeiro, Brasil) e transportadas ao laboratório para uso imediato.

\subsection{Preparação da cenoura minimamente processada}

As cenouras foram adquiridas em 2 supermercados na zona sul do Rio de Janeiro, Brasil, caracterizando 2 lotes. Em seguida transportadas para o laboratório, sendo armazenadas em temperatura de $4^{\circ} \mathrm{C} / 12 \mathrm{~h}$, para remoção do calor. As cenouras foram adequadamente lavadas com 
água destilada depois de terem sido sanitizadas durante 30 minutos em um banho contendo 200 ppm de hipoclorito de sódio. Todos os equipamentos e utensílios utilizados também foram convenientemente higienizados. Os cortes foram feitos mecanicamente, com auxílio de um multiprocessador marca Fun Kitchen ${ }^{\circledR}$. Parte desta amostra foi reservada para o controle.

\subsection{Elaboração de solução para revestimento}

Para a elaboração dos revestimentos foi preparada uma solução filmogênica obtida mediante a extração da FFH em água a $70^{\circ} \mathrm{C} / 45$ min. com agitação constante, posteriormente a solução foi filtrada em filtros de poliéster e então centrifugada, sendo utilizado apenas o sobrenadante.

\subsection{Aplicação dos revestimentos em cenoura minimamente processada}

As amostras após processamento mínimo, foram imersas na solução filmogênica por 5 minutos, drenadas e secas em temperatura ambiente por 90 minutos. O controle, foi imerso em água destilada nas mesmas condições. As amostras foram acondicionadas em potes tampados de poliestireno e armazenadas a $5^{\circ} \mathrm{C}$, em câmara climática por até 12 dias.

\subsection{Vida de prateleira}

Perda de massa: A variação de massa das amostras foi determinada pesando-se as embalagens em balança semi-analítica, a cada três dias, durante o armazenamento). As análises foram realizadas em triplicata.

Indice de esbranquiçamento (IE): Os parâmetros diferença de cor $(\Delta \mathrm{E})$, croma $\mathrm{a}^{*}$, croma $\mathrm{b}^{*}, \mathrm{~L}^{*}$ e foram determinados de acordo com Botrel et al. (2010), utilizando-se um colorímetro da marca Konica Minolta. As análises colorimétricas foram realizadas em triplicata. O IE foi determinado de acordo com Pereira et al. (2008). Os resultados foram expressos, utilizando- se o parâmetro do IE de acordo com a Equação:

$$
I E=100-\left[\left(100-L^{*}\right)^{2}+a^{* 2}+b^{* 2}\right]^{1 / 2}
$$

$\mathrm{L}^{*}=$ luminosidade ou brilho do produto (claro/escuro); $\mathrm{a}^{*}=$ cromaticidade no eixo verde (-) para vermelho $(+) ; b^{*}=$ cromaticidade no eixo da cor azul (-) para amarelo (+). 


\subsection{Análises químicas e físico-químicas}

Todas as amostras foram avaliadas em triplicata no tempo zero e a cada 3 dias de armazenamento através dos seguintes parâmetros químicos e físico-químicos: Sólidos Solúveis Totais (SST) determinados por leitura direta em refratômetro, corrigido em relação à temperatura com resultados expressos em ${ }^{\circ}$ Brix; Acidez Total Titulável (ATT) por titulometria com resultados expressos em \% de ácido cítrico; pH determinado através de potenciômetro digital (Gonçalves, 2006).

\subsection{Tratamento estatístico}

Os resultados obtidos foram analisados pelo teste de Tukey a nível de 5\% de significância utilizando-se o programa ASSISTAT versão 7.7 beta.

\section{RESULTADOS E DISCUSSÃO}

O parâmetro perda de massa foi o único que não apresentou diferença significativa entre os lotes, sendo representado pela média dos mesmos, Tabela 1. Observa-se que o tratamento com a solução filmogênica não influenciou nesta análise, tendo ocorrido comportamento similar em estudo relatado por Henrique e Evangelista (2006) ao aplicar películas biodegradáveis a base de amido em cenoura minimamente processada. Acredita-se que o acondicionamento em pote de poliestireno, o qual apresenta boa barreira à permeabilidade a vapor de água, explica a não diferença na perda de massa, fato este observado por Botrel et al. (2007).

O IE aumentou, de forma significativa, no $12^{\circ}$ dia de armazenamento, apenas para as amostras do lote 1 , mas o tratamento com solução filmogênica não influenciou no resultado, sendo similar ao controle. O comportamento das amostras do lote 2 foi diferente, mesmo somente a amostra tratada apresentando aumento significativo do IE no $12^{\circ}$ dia de armazenamento, este se mantém inferior na comparação com o controle, Gráfico 1. A ocorrência de alterações estruturais das células nas camadas mais externas do alimento minimamente processado, que ocorre de maneira irreversível, justifica o aumento do IE. Observa-se também aumento do IE no decorrer do tempo de conservação, justificado por ação natural reversível que ocorre devido à injúria tecidual, por desidratação superficial do produto, bem como por modificações fisiológicas no metabolismo de fenólicos, causados pela abrasão durante o processamento que geraria um acúmulo superficial de compostos fenólicos não estruturais, o qual estaria ligado ao aumento da atividade da enzima fenilalanina amônia-liase. (Simões et al., 2010; Pereira et al., 2008; Emmambux et al., 2004) 
Tabela 1 - Valores médios obtidos para as análises físico-químicas e químicas de cenoura minimamente processada ralada com e sem revestimento armazenada $5^{\circ} \mathrm{C}$ por 12 dias

\begin{tabular}{|c|c|c|c|c|c|}
\hline Amostras & Dia 0 & Dia 3 & Dia 6 & Dia 9 & Dia 12 \\
\hline \multicolumn{6}{|c|}{ Perda de Massa (\%) } \\
\hline $\mathrm{C}$ & - & $0.529 \pm 0.328^{\mathrm{Abc}}$ & $1.471 \pm 0.225^{\mathrm{Ab}}$ & $2.444 \pm 0.438^{\mathrm{Aa}}$ & $3.432 \pm 0.860^{\mathrm{Aa}}$ \\
\hline SF & - & $0.713 \pm 0.077^{\mathrm{Acd}}$ & $1.532 \pm 0.197^{\mathrm{Abc}}$ & $2.488 \pm 0.354^{\mathrm{Ab}}$ & $4.156 \pm 1.118^{\mathrm{Aa}}$ \\
\hline \multicolumn{6}{|c|}{ IE (\%) } \\
\hline CL1 & $26.541 \pm 1.345^{\mathrm{ABd}}$ & $28.118 \pm 0.654^{\mathrm{ABcd}}$ & $29.562 \pm 0.449^{\mathrm{ABbc}}$ & $31.444 \pm 0.299^{\mathrm{Ad}}$ & $34.074 \pm 0.323^{\mathrm{Aa}}$ \\
\hline SFL1 & $23.996 \pm 1.585^{\mathrm{Bd}}$ & $26.989 \pm 1.038^{\mathrm{Bc}}$ & $29.073 \pm 0.778^{\mathrm{ABbc}}$ & $30.781 \pm 0.745^{\mathrm{Ab}}$ & $33.487 \pm 0.476^{\mathrm{Aa}}$ \\
\hline CL2 & $28.176 \pm 1.297^{\mathrm{Ab}}$ & $29.940 \pm 1.133^{\mathrm{Aab}}$ & $30.576 \pm 1.294^{\mathrm{Aab}}$ & $30.349 \pm 1.958^{\mathrm{Aab}}$ & $31.974 \pm 0.876^{\mathrm{Ba}}$ \\
\hline SFL2 & $25.400 \pm 0.460^{\mathrm{ABd}}$ & $27.362 \pm 0.419^{\mathrm{Bc}}$ & $28.358 \pm 0.445^{\mathrm{Bbc}}$ & $29.316 \pm 0.419^{\mathrm{Aab}}$ & $30.430 \pm 0.448^{\mathrm{Ca}}$ \\
\hline \multicolumn{6}{|c|}{ ATT (\% Ácido Cítrico) } \\
\hline CL1 & $0.012 \pm 0.001^{\mathrm{Bb}}$ & $0.009 \pm 0.001^{\mathrm{Bc}}$ & $0.011 \pm 0.001^{\mathrm{Cbc}}$ & $0.016 \pm 0.002^{\mathrm{Ba}}$ & $0.017 \pm 0.001^{\mathrm{Aa}}$ \\
\hline SFL1 & $0.042 \pm 0.004^{\mathrm{Ab}}$ & $0.027 \pm 0.003^{\mathrm{Ac}}$ & $0.053 \pm 0.000^{\mathrm{Aa}}$ & $0.017 \pm 0.004^{\mathrm{Bd}}$ & $0.012 \pm 0.000^{\mathrm{Bd}}$ \\
\hline CL2 & $0.015 \pm 0.004^{\mathrm{Bb}}$ & $0.014 \pm 0.004^{\mathrm{Bb}}$ & $0.012 \pm 0.001^{\mathrm{Cb}}$ & $0.052 \pm 0.001^{\mathrm{Aa}}$ & $0.013 \pm 0.001^{\mathrm{Bb}}$ \\
\hline SFL2 & $0.040 \pm 0.004^{\mathrm{Aa}}$ & $0.035 \pm 0.005^{\mathrm{Aa}}$ & $0.021 \pm 0.005^{\mathrm{Bb}}$ & $0.014 \pm 0.002^{\mathrm{Bb}}$ & $0.018 \pm 0.002^{\mathrm{Ab}}$ \\
\hline \multicolumn{6}{|c|}{ pH } \\
\hline CL1 & $5.987 \pm 0.047^{\mathrm{Ab}}$ & $6.153 \pm 0.046^{\mathrm{ABa}}$ & $5.950 \pm 0.026^{\mathrm{Bbc}}$ & $5.770 \pm 0.017^{\mathrm{Cd}}$ & $5.883 \pm 0.040^{\mathrm{Bc}}$ \\
\hline SFL1 & $5.330 \pm 0.017^{\mathrm{Cd}}$ & $6.213 \pm 0.015^{\mathrm{Aa}}$ & $6.187 \pm 0.021^{\mathrm{Aab}}$ & $5.950 \pm 0.061^{\mathrm{BCc}}$ & $6.127 \pm 0.021^{\mathrm{Ab}}$ \\
\hline CL2 & $5.887 \pm 0.023^{\mathrm{Bb}}$ & $6.107 \pm 0.031^{\mathrm{Ba}}$ & $6.147 \pm 0.029^{\mathrm{Aa}}$ & $6.093 \pm 0.125^{\mathrm{Ba}}$ & $6.040 \pm 0.040^{\mathrm{Aab}}$ \\
\hline SFL2 & $5.270 \pm 0.020^{\mathrm{Cd}}$ & $6.020 \pm 0.026^{\mathrm{Cc}}$ & $6.157 \pm 0.012^{\mathrm{Ab}}$ & $6.333 \pm 0.029^{\mathrm{Aa}}$ & $6.120 \pm 0.070^{\mathrm{Abc}}$ \\
\hline
\end{tabular}

Médias seguidas de mesma letra, maiúscula nas colunas e minúscula nas linhas, não diferem pelo teste Tukey (p>0,05). CL1: cenoura sem revestimento lote 1; SFL1: cenoura com revestimento lote 1; CL2: cenoura sem revestimento lote 2; SFL2: cenoura com revestimento lote 2; C: média C1 e C2; SF: média SF1 e SF2.

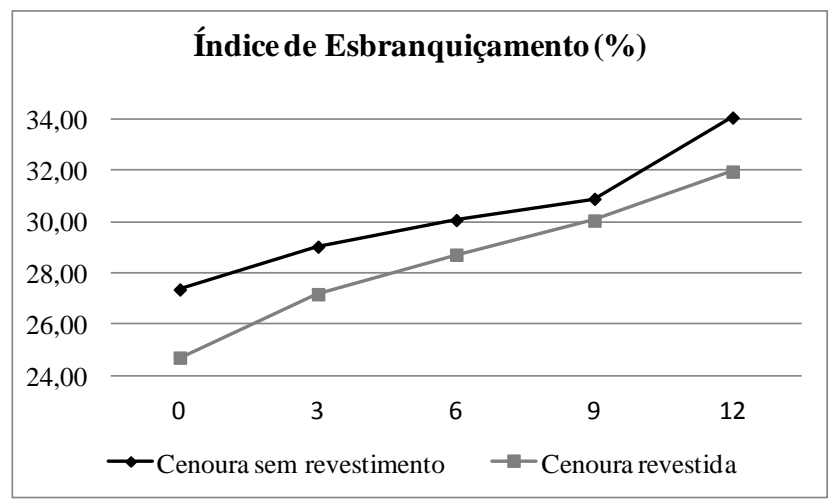

Gráfico 1 - Índice de esbranquiçamento (\%) de cenoura minimamente processada ralada com e sem revestimento armazenada $5{ }^{\circ} \mathrm{C}$ por 12 dias. 


\section{9 a 22 de outubro de 2014 \\ Florianópolis/SC}

O teor de ${ }^{\circ}$ Brix iniciou em média com 1,8 e 2,4 respectivamente para amostra controle e tratada. Durante o armazenamento o comportamento foi similar havendo decréscimo linear de aproximadamente $0,4^{\circ}$ Brix no $12^{\circ}$ dia. Essa diminuição pode ser atribuída à degradação do produto durante o armazenamento (Pereira et al., 2008).

Os teores de acidez total titulável (ATT) das amostras variou de forma complexa ao longo do experimento. Parte das amostras apresentou uma tendência de aumento pontual seguido de redução durante o armazenamento. Em uma observação inicial, pode-se acreditar que a amostra tratada promoveu uma redução da acidez superior ao controle, mas considerando que a solução filmogênica apresenta pH em torno de 4,0 (Andrade,2013), justifica-se o aumento inicial da acidez. Todas as amostras, no final do experimento, apresentaram acidez similar ou com irrelevante diferença quando comparado às amostras controle no tempo 0.

O parâmetro $\mathrm{pH}$ apresentou comportamento similar ao descrito para ATT, onde as amostras tratadas iniciaram com $\mathrm{pH}$ mais ácido que as do controle, conforme esperado, e no final com pequenas variações na comparação com as amostras controle tempo 0 . O perfil de mudança do $\mathrm{pH}$ e os valores encontrados assemelham-se aos obtidos por Kohatsu et al. (2009) e Henrique \& Evangelista (2006) avaliando as características de cenouras minimamente processadas com e sem revestimento polissacarídico, respectivamente.

\section{CONCLUSÃO}

O uso de revestimento a base de frutas e hortaliças não influenciou na vida de prateleira de cenouras minimamente processadas, com exceção do índice de esbranquiçamento, constantando que a solução aplicada influenciou na redução deste parâmetro ao retardar o esbranquiçamento superficial. Considerando os constituintes da solução filmogênica com potencial antioxidante esta pode ser hábil em diminuir a perda de carotenóides e outros compostos bioativos da amostra, além de agregar valor funcional e melhorar características sensoriais de sabor e aroma. Assim, este estudo segue em andamento visando verificar o teor de compostos bioativos nas cenouras minimamente processadas revestidas, mensurar suas características microbiológicas e sensoriais.

\section{REFERÊNCIAS}

AHMED, L., MARTIN-DIANA, A.B., RICO, D., \& BARRY-RYAN, C.. Quality and nutritional status of fresh-cut tomato as affected by spraying of delactosed whey permeate compared to industrial washing treatment. Food and Bio. Tech., 2011.

ALARCÓN-FLORES, M. I.; ROMERO-GONZÁLEZ, R.; VIDAL, J. L. M.; GONZÁLEZ, F. J. E.; FRENICH, A. G.. Monitring of phytochemicals infresh and fresh-cut vegetables: A comparison. Food Chemistry, Elsevier. v. 142, p. 392-399, 2014. 
ANDRADE, R.M.S. (2013). Desenvolvimento e caracterização de filmes biodegradáveis à base de resíduos de frutas e hortaliças. 2013. 70p. Dissertação (Mestrado em Alimentos e Nutrição) Universidade Federal do Estado do Rio de Janeiro.

AZEREDO, H. M. C,; MIRANDA, K. W. E.; ROSA, M. F.; NASCIMENTO, D. M.; MORA, M. R.. Edible films from alginate-acerola puree reinforced with cellulose whiskers. LWT-Food Sci. and Tech., v.46, p.294-297, 2012.

BARbOSA, H. R.; ASCHERI, R. P. R.; ASCHERI, J. L. R.; CARVAlHO, C. W. P.. Permeabilidade, estabilidade e funcionalidade de filmes biodegradáveis de amido de caroço de jaca (Artocarpus heterophyllus). Revista Agrotec., v.2, p.73-88, 2011.

BOTREL, D.A.; SOARES, N.F.F.; CAMILLOTO, G.P.; FERNANDES, R.V.B.. Revestimento ativo de amido na conservação pós-colheita de pera Williams minimamente processada. Ciênc. Rural, v.40, n.8, p.1814-1820, 2010.

DU, W.-X., OlSEN, C. W., AVENA-BUSTIlloS, R. J., FRIEDMAN, M.; MCHUGH, T. H.. Physical and antibacterial properties of edible films formulated with apple skin polyphenols. $J$. of Food Scie., v. 76, n. 2, p. 149-155, 2011.

EMMAMBUX, M. N.; LANNACE, S.; STADING, M.. Cereal biopolymer films, coating and other industrial products. Chemic. Tech.. (1):27-31. 2004.

FERREIRA, M S. L.; SANTOS, M C. P; MORO, T.M. A.; BASTO, G J.; ANDRADE, R M. S.; GONÇALVES, E C. B. A.. Formulation and characterization of functional foods based on fruit and vegetable residue flour. J. of Food Scie. and Tech. 2013.

GONÇALVES, E. C. B. A.. Análise de Alimentos. Uma Visão Química da Nutrição. $2^{\mathrm{a}}$ Edição. Livraria Varela. 2006.

HENRIQUE, C.M.; EVANGELISTA, R.M. Processamento mínimo de cenouras orgânicas com uso de películas biodegradáveis. Publicatio UEPG: Ciênc. Ex. e da Terra, Ciênc. Agr. e Eng., v. 12, n.3, p.7-14, 2006.

KOHATSU, D.S.; EVANGELISTA, R.M.; SEABRA JR, S.S.; VIEITES, R.L.; GOTO, R. Características físicas, físico-químicas, químicas e sensoriais de cenoura minimamente processada. Cascavel, v.2, n.4, p.57-68, 2009

MARTELLI, M.; MOURA, M. R.; BARROS, T. T.; ASSIS, O.B.G.. Edible films based on over-ripe bananas, pectin and chitosan nanoparticles. X Brazilian MRS Meeting, 2011, Gramado. X Brazilian MRS Meeting, 2011.

MARTINS, R. C.; CHIAPETTA, S. C.; PAUlA, F. D.; GONÇAlVES, E. C. B. A.. Evaluation isotonic drink fruit and vegetables shelf life in 30 days. Bra. J. of Food Nutr., v. 22, n. 4, p. 623-629, 2011. 
OOI, Z.X.; ISMAIL, H.; BAKAR, A.A., AZIZ, N. A. A. Properties of the Crosslinked Plasticized Biodegradable Poly(vinyl alcohol)/Rambutan Skin Waste Flour Blends. J. of Ap. Pol. Scie., v. 125, p.1127-1135, 2012.

PARK, S.; ZHAO, Y.. Development and characterization of edible films from cranberry pomace extracts. J. of Food Scie.. V.71, p. 95-101, 2006.

PEREIRA, J.M.A.K; MINIM, V.P.R.; PUSCHMANN, R.; VANETTI, M.C.D.; SOARES, N.F.F.; MORETTI, C.L. VIEIRA, J.V.. Qualidade físico-química de mini-cenouras revestidas. Rev. Ceres, v.55, n.6, p.537-542, 2008.

PORTA R.; ROSSI-MARQUEZ, G.; MARINIELLO, L.; SORRENTINO A.; GIOSAFATTO V.; ESPOSITO, M.; PIERRO, P.D. Edible Coating as Packaging Strategy to Extend the Shelf-life of Fresh- Cut Fruits and Vegetables. J. of Biotech. \& Biomat.. 2013.

SIMÕES, A. N.; VENTRELLA, M. C.; MORETTI, C. L.; CARNELOSSI, M. A. G.; PUSCHMANN, R.. Anatomical and physiological evidence of white brush on baby carrot surfaces. Post. Biol. and Tech., Elsevier. v. 55, i. 1, p. 45-52, 2010. 